\title{
Does the interval from tumour surgery to radiotherapy influence survival in paediatric high grade glioma?
}

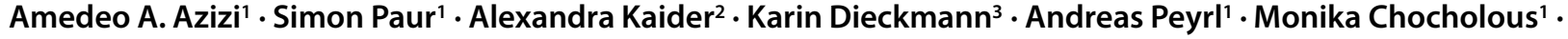 \\ Thomas Czech4 $\cdot$ Irene Slavc'
}

Received: 15 November 2017 / Accepted: 5 January 2018 / Published online: 18 January 2018

(c) The Author(s) 2018. This article is an open access publication.

\begin{abstract}
Purpose Paediatric high grade glioma (pHGG) are rare. Following maximum safe resection, children $>3$ years with HGG receive radiotherapy as standard of care. Whether the interval from tumour surgery to radiotherapy (ISRT) influences survival is disputed in adults with glioblastoma, data for children are lacking. This retrospective single-centre analysis investigates a possible impact of ISRT on survival in paediatric patients with HGG.

Methods Survival was analysed in patients aged 3-19 years with non-pontine HGG.

Results Thirty-eight patients were included (female:male 19:19) with a median age of 11.0 years (3.4-17.7). Seventeen patients had grade 3 and 21 grade 4 glioma. Gross total resection was achieved in 26.3\%, partial resection in $36.8 \%$ and $36.8 \%$ underwent biopsy only. All patients received concomitant and adjuvant chemotherapy. Fifty percent $(n=19)$ started irradiation $\leq 17$ days (median interval 12 days [range 5-17]), 50\% thereafter (median 28 days [range 19-78]). More patients with grade 4 tumours were irradiated shortly after surgery. ISRT (as a continuous variable and dichotomised into two groups by the median ISRT of 18 days) did not significantly influence overall survival (OS) or progression-free survival (PFS). Higher extent of resection (EOR), lower tumour grade as well as chemotherapy with temozolomide had a significant positive impact on OS and PFS in univariate analysis and (except for the effect of temozolomide on PFS) also in multivariable analysis.

Conclusions ISRT did not influence survival in pHGG. In view of upcoming targeted treatment options in pHGG the present data suggest that it is safe to perform molecular analyses within a 4-week timeframe before radiotherapy.
\end{abstract}

Keywords Radiotherapy $\cdot$ High grade glioma $\cdot \mathrm{HGG} \cdot$ Children $\cdot$ Paediatric oncology

Amedeo A. Azizi

amedeo.azizi@meduniwien.ac.at

1 Department of Pediatrics and Adolescent Medicine, Medical University of Vienna, Spitalgasse 23, 1090 Vienna, Austria

2 Center for Medical Statistics, Informatics, and Intelligent Systems, Medical University of Vienna, Vienna, Austria

3 Department of Radiation Oncology, Medical University of Vienna, Vienna, Austria

4 Department of Neurosurgery, Medical University of Vienna, Vienna, Austria 


\section{Beeinflusst die Zeitspanne zwischen Tumorresektion und Strahlentherapie das Überleben bei Kindern mit hochgradigen Gliomen?}

\section{Zusammenfassung}

Zielsetzung Hochgradige Gliome bei Kindern (pHGG) sind selten. Als Therapiestandard gilt die Tumorresektion gefolgt von Strahlentherapie. Ein möglicher Einfluss des zeitlichen Intervalls zwischen Tumorresektion und Radiotherapie (ISRT) auf das Überleben wird bei Erwachsenen kontroversiell diskutiert. Daten bei Kindern fehlen bis dato. Diese retrospektive unizentrische Studie analysiert das ISRT und dessen möglichen Einfluss auf das Überleben bei pädiatrischen HGG-Patienten.

Methoden Bei Patienten im Alter zwischen 3-19 Jahren mit nichtpontinem HGG wurde eine Überlebensanalyse durchgeführt.

Ergebnisse In die Studie konnten 38 Patienten eingeschlossen werden (weiblich:männlich 19:19; medianes Alter 11,0 Jahre [Spanne 3,4-17,7]). 17 Patienten hatten ein Gliom WHO Grad 3 und 21 Patienten vom Grad 4. Eine Totalresektion erhielten 26,3\%, eine Teilresektion bzw. eine Biopsie je 36,8\%. Alle Patienten bekamen eine konkomitante und adjuvante Chemotherapie. Jeweils 50\% $(n=19)$ begannen die Bestrahlung $\leq 17$ Tage (medianes Intervall 12 Tage [Spanne 5-17]), 50\% danach (Median 28 Tage [Spanne 19-78]). Mehr Patienten mit WHO-Grad-4-Tumoren wurden knapp nach der Operation bestrahlt. ISRT (als kontinuierliche Variable und dichotomisiert in zwei Gruppen mittels medianem ISRT von 18 Tagen) hatte keinen Einfluss auf Gesamtüberleben (OS) oder progressionsfreies Überleben (PFS). Ein größeres Ausmaß der Resektion, niedrigerer Tumorgrad und Chemotherapie mit Temozolomid hatten einen signifikant positiven Einfluss auf OS und PFS in univariater und auch in multivariabler Analyse (außer für den Effekt von Temozolomid auf das PFS).

Schlussfolgerung ISRT hat keinen Einfluss auf das Überleben bei pHGG. Angesichts neuer gezielter Behandlungsansätze bei pHGG erscheint aufgrund der gegenwärtigen Daten eine Frist von 4 Wochen als sicher, um eine molekulare Analyse vor Beginn der Strahlentherapie durchzuführen.

Schlüsselwörter Strahlentherapie · Radiotherapie · Hochgradiges Gliom · HGG · Kinder · Pädiatrische Onkologie

\section{Introduction}

Prognosis of high grade glioma (HGG) in childhood is similarly poor as in adults. Standard of care in children with HGG older than three years of age includes maximal safe resection followed by focal radiotherapy (RTX) and variable adjuvant chemotherapy (CTX). Because HGGs are fast growing, aggressive malignancies neuro-oncology practice usually aims at minimising delay to initiation of RTX after surgery. More recently though, several distinct epigenetic and biological subgroups of HGG gliomas in children were described requiring determination of molecular markers for treatment stratification in future trials [1], thus most likely leading to longer delays in initiation of treatment. Yet no data exist in the paediatric HGG population whether the interval from surgery to initiation of radiotherapy (ISRT) influences survival. From a biological point of view and considering growth dynamics of malignant solid tumours such as high grade glioma an increased risk of relapse and a subsequent negative impact on survival may be postulated [1]. In adults delayed initiation of RTX was indeed proven to negatively impact outcome in head and neck, breast and other cancers [2]. In recent years an increasing number of studies investigated ISRT in adult patients with HGG, but results remain conflicting. Whereas some studies could identify the expected negative impact on survival
[3-7], others failed to show any correlation with survival [8-12]. Some large studies even suggest a positive effect of moderately delayed RTX on survival in adult patients with HGG [13-18].

The present institutional study investigates whether the interval between surgery and initiation of RTX influences survival in paediatric patients with HGG.

\section{Methods}

Patients with HGG treated at the Department of Paediatrics, Medical University of Vienna, Austria, from 1995 to 2015 were included in this retrospective single-centre analysis. The following eligibility criteria had to be met: histologically confirmed high-grade glioma (WHO grades 3 or 4), age 3-19 years at diagnosis, application of postoperative adjuvant radiation therapy and sufficient clinical data on primary treatment and follow-up. Patients with diffuse intrinsic brainstem glioma (DIPG) were excluded, as well as patients with a secondary tumour following prior cranial RTX. Patients younger than three years were excluded as RTX is generally withheld in these children [19]. Followup was conducted according to institutional standards (Table 1) and was continued at the Department of Paediatrics even after patients had reached adulthood. 
Table 1 Institutional follow-up for patients with paediatric high grade glioma
Clinical and neurological examination

Local MRI (i.e. brain or spine)

Neuro-axis MRI

Endocrine surveillance

Hearing

Neuropsychological testing and support

Other (e.g. ophthalmology, bone age, orthopaedics, dermatology)

$M R I$ magnetic resonance imaging

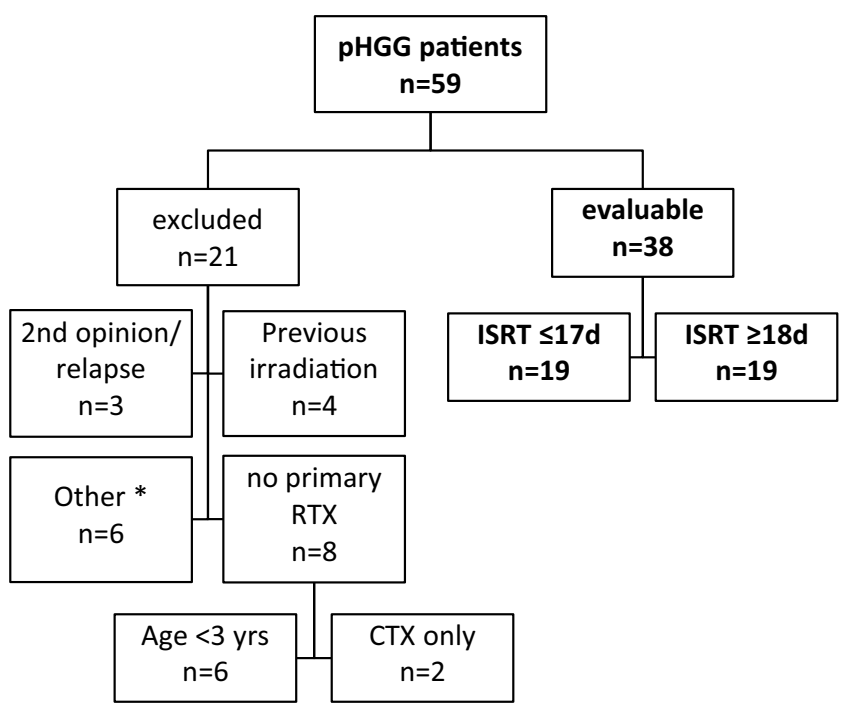

Fig. 1 Patient evaluation. ( ${ }^{\text {asterisk }}$ Other excluded patients: $n=2$ tumour reclassified (Glioblastoma $\rightarrow$ atypical teratoid/rhabdoid tumour; anaplastic astrocytoma $\rightarrow$ pleomorphic-xanthoastrocytoma $\left.\mathrm{WHO}^{\circ} \mathrm{II}\right)$; $n=1$ died before surgery; $n=1$ RTX discontinued by choice of the parents after 2 weeks at a dose of $22.0 \mathrm{~Gy} ; n=2$ insufficient quality of available data. CTX chemotherapy, $d$ days, ISRT interval from surgery to radiotherapy, $p H G G$ paediatric high grade glioma, $R T X$ radiotherapy, yrs years)

This retrospective analysis was approved by the ethical review board of the Medical University of Vienna.

\section{Statistical analysis}

Statistical calculations and graphical representation of results was performed using SAS (version 9.4, SAS Institute Inc. [2002-2012], Cary, NC, USA). Comparisons between patient groups with respect to categorical variables were performed using the Chi-square test. The median follow-up times were estimated by the inverse Kaplan-Meier method
[20]. Probabilities of progression-free survival (PFS) and overall survival (OS) were calculated by the Kaplan-Meier method and differences in the survival probabilities between patient groups were tested by the log-rank test [21]. Univariate and multivariable Cox regression models [22] were used to evaluate the unadjusted and adjusted effects of the ISRT (in days), the extent of resection (EOR, ranging from biopsy (1) to gross total (4)) and WHO grading (4 vs. 3) on PFS and OS, respectively. Log2-transformed values of ISRT were used for statistical analyses because of their skewed distribution. Additional exploratory analyses were performed, evaluating ISRT and EOR as binary variables, categorizing ISRT according to the median value ( $\geq 18$ days vs. $\leq 17$ days) and EOR comparing gross total resection to all other resections combined including biopsy. Furthermore, age (in years) was evaluated in univariate regression models as potential prognostic factor for OS and PFS. The Firth correction [23] was used in all Cox regression analyses to reduce bias in the estimates resulting from the rather small sample size. Two-sided $p$-values $<0.05$ were considered as indicating statistical significance.

\section{Results}

The medical histories of 59 patients with HGG were evaluated; 38 of them met the above mentioned criteria (Fig. 1). All patients received radiochemotherapy (RCTX) following surgery. Patient characteristics are listed in Table 2. According to a median ISRT of 18 days, the cohort was divided in two groups: group 1 started simultaneous RCTX within 17 days of surgery, group 2 after $\geq 18$ days. An exploratory analysis also evaluated the impact of an ISRT of \pm 28 days (see below). 
Table 2 Patient characteristics

\begin{tabular}{|c|c|c|c|c|}
\hline & & $\begin{array}{l}\text { Group } 1 \\
\text { ISRT } \leq 17 \mathrm{~d}\end{array}$ & $\begin{array}{l}\text { Group } 2 \\
\text { ISRT } \geq 18 \mathrm{~d}\end{array}$ & Total \\
\hline \multirow[t]{2}{*}{$\overline{S e x}$} & Male & $9(47.4 \%)$ & $10(52.6 \%)$ & $19(50.0 \%)$ \\
\hline & Female & $10(52.6 \%)$ & $9(47.4 \%)$ & $19(50.0 \%)$ \\
\hline \multirow[t]{2}{*}{ Age } & $3-10$ & $7(36.8 \%)$ & $12(63.2 \%)$ & $18(47.4 \%)$ \\
\hline & $11-19$ & $12(63.2 \%)$ & $7(36.8 \%)$ & $20(52.6 \%)$ \\
\hline \multirow[t]{2}{*}{ Grading } & WHO grade III & $6(31.6 \%)$ & $11(57.9 \%)$ & $17(44.7 \%)$ \\
\hline & WHO grade IV & $13(68.4 \%)$ & $8(42.1 \%)$ & $21(55.3 \%)$ \\
\hline \multirow[t]{4}{*}{ Location } & Hemispheric & $10(60.0 \%)$ & $10(53.3 \%)$ & $20(52.6 \%)$ \\
\hline & Diencephalic & $8(33.3 \%)$ & $8(40.0 \%)$ & $16(42.1 \%)$ \\
\hline & Spinal & $1(6.7 \%)$ & $0(0.0 \%)$ & $1(2.6 \%)$ \\
\hline & Multifocal & $0(0.0 \%)$ & $1(6.7 \%)$ & $1(2.6 \%)$ \\
\hline \multirow{4}{*}{$\begin{array}{l}\text { Extent of resection } \\
(E O R)\end{array}$} & Gross total & $5(26.3 \%)$ & $5(26.3 \%)$ & $10(26.3 \%)$ \\
\hline & Subtotal & $4(21.1 \%)$ & $3(15.8 \%)$ & $7(18.4 \%)$ \\
\hline & Partial & $2(10.5 \%)$ & $5(26.3 \%)$ & $7(18.4 \%)$ \\
\hline & Biopsy & $8(42.1 \%)$ & $6(31.6 \%)$ & $14(36.8 \%)$ \\
\hline \multirow[t]{2}{*}{ Follow-up (median) } & Overall & 62.2 months & 56.6 months & 60.7 months \\
\hline & Range (in months) & $6.9-89.2$ & $76.6-169.4$ & $6.9-169.4$ \\
\hline$n(\%)$ of total cohort & & $19(50.0 \%)$ & $19(50.0 \%)$ & $38(100 \%)$ \\
\hline
\end{tabular}

CTX chemotherapy, $H G G$ high grade glioma, ISRT interval from surgery to radiotherapy, RTX radiotherapy, WHO World Health Organisation

Table 3 Chemotherapy regimens applied for HGG treatment

\begin{tabular}{lll}
\hline CTX regimen & $n=$ & $\%$ \\
\hline HIT-GBM-D [37] & & \\
$\quad$ MTX window & 9 & 34.2 \\
$\quad$ No window therapy & 4 & 10.5 \\
PEI-based CTX incl. & 11 & 29.0 \\
HIT-GBM-C [36] & & \\
Temozolomide, Stupp-like regimen [38] & 10 & 26.3 \\
GBM-VAX [39] Dendritic cell vac- & 2 & 5.3 \\
cine + Stupp regimen & & \\
VCR 1.5 mg/m ${ }^{2}$ weekly during RTX & 1 & 2.6 \\
Nimotuzumab + vinorelbin [40, 41] & 1 & 2.6 \\
\hline
\end{tabular}

MTX Methotrexate, PEI Cisplatin, Etoposide, Ifosfamide, RTX Radiotherapy, $V C R$ Vincristine

GBM-VAX, HIT-GBM-D and HIT-GBM-C are protocol names

\section{Descriptive analysis}

Patient characteristics The median age at diagnosis was 11.0 years (3.4-17.7); the mean age was 11.3 years (SD 4.24). Age as well as sex were evenly distributed between study groups. Histology revealed 17 WHO grade 3 and 21 grade 4 tumours, including three cases of gliomatosis. There were more patients with grade 4 tumours in group 1 than group 2, yet the difference was not statistically significant (Chi-square testing $p=0.10$ ). Except for one case of a spinal glioblastoma, all tumours were located supratentorially, 7 (18.4\%) bilaterally. Sixteen tumours were located in the supratentorial midline ( $42.1 \%)$; primary leptomeningeal dissemination was present in a single case of glioblastoma WHO grade 4.
Extent of resection (EOR) A gross total resection (GTR) was achieved in $10(26.3 \%)$, near total/subtotal resection and partial resection each in 7 patients $(18.4 \%)$. Fourteen patients $(36.8 \%)$ underwent a biopsy only. The number of patients with GTR was comparable in groups 1 and 2 .

Radiotherapy Of all patients, $84.2 \%(n=32)$ underwent focal conformal cranial RTX, the patient with spinal GBM underwent focal spinal RTX and four underwent wholebrain irradiation because of gliomatosis cerebri or multifocal GBM. The single patient with primary leptomeningeal disease received craniospinal irradiation. The mean duration of RTX was 6.2 weeks. Median dose applied was $59.4 \mathrm{~Gy}(50-66.0 \mathrm{~Gy})$. Two thirds of all patients $(n=24)$ received a dose $\geq 59.4 \mathrm{~Gy}$, delivered in fractions varying from 1.6-2.0 Gy. No severe side effects were reported.

Adjuvant chemotherapy All 38 patients received adjuvant systemic therapies. Details are listed in Table 3.

Survival By the end of data accrual (12/2015), 31/38 patients $(81.6 \%)$ had experienced progression or disease recurrence; $30 / 38$ (78.9\%) had died. Median follow-up was 60.7 months (6.9-169.4). Median PFS was 10.4 months, with 1-, 2- and 5-year progression-free survival rates of $42.1 \%, 23.7 \%$ and $18.1 \%$, respectively. Seventeen of 31 patients $(54.8 \%)$ with disease progression/recurrence were switched to alternative chemotherapy protocols and $6(19.4 \%)$ were re-irradiated, followed by alternative chemotherapy in three. In 6 patients, only supportive care was provided at the time of relapse. Documentation on re- 

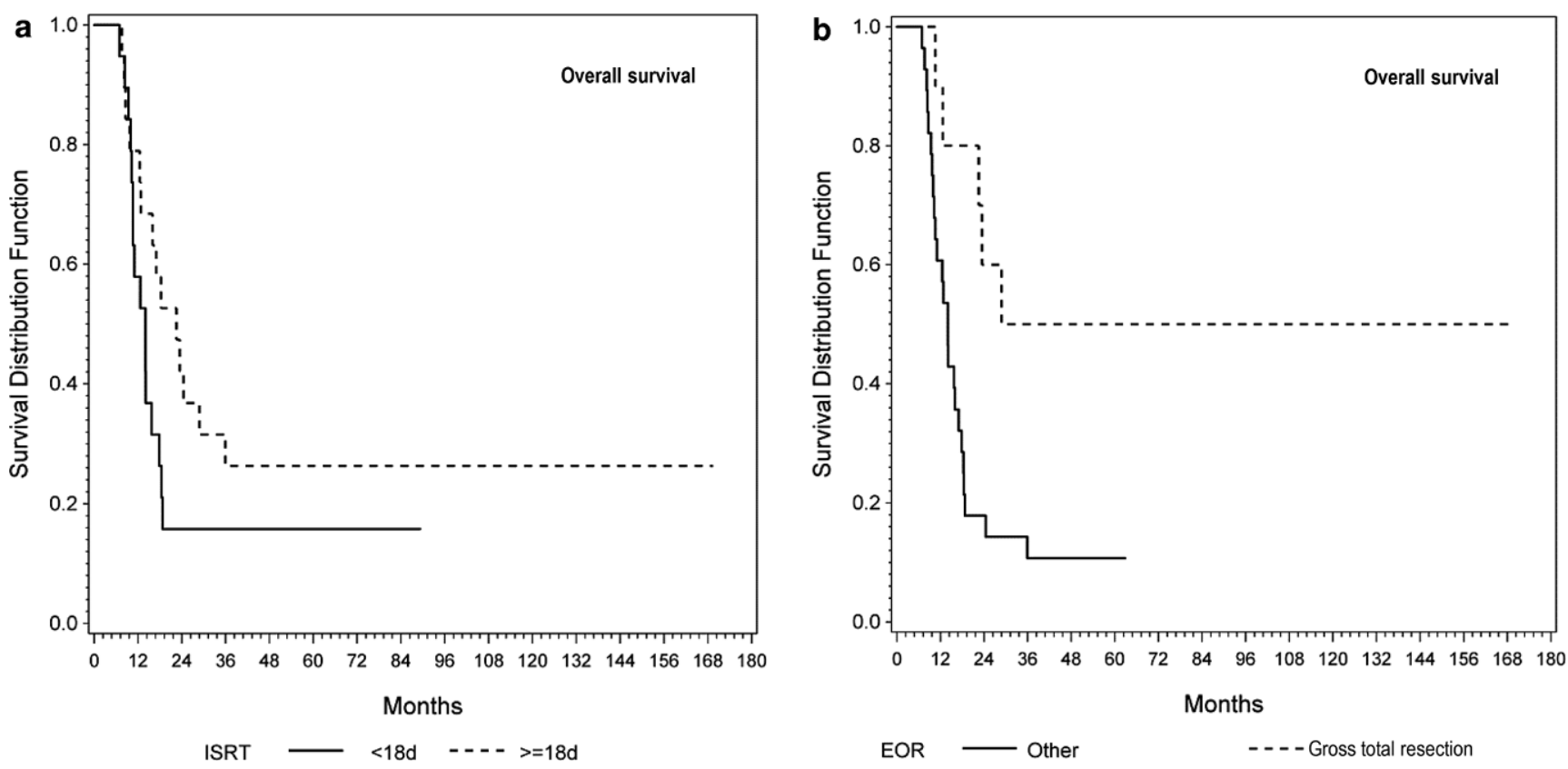

Fig. 2 Overall survival. a There was no difference in overall survival between patients with an ISRT of $\leq 17$ days vs. $\geq 18$ days (log-rank: $p=0.143$ ). b EOR: patients with gross total resection achieved a significantly superior overall survival when compared to all other patterns of resection $(p=0.007)$. (EOR extent of resection; ISRT interval from surgery to radiotherapy)

lapse therapy was missing in 2 patients. Only $1 / 31$ patients with recurrence is still alive for more than 5 years after primary diagnosis following lysate-pulsed dendritic cell (DC) vaccination at diagnosis and renewed DC vaccination after re-surgery and re-irradiation. Survivors were evenly distributed between groups ( 3 in group 1, 5 in group 2). Five of eight $(62.5 \%)$ survivors had GTR. Median OS was 15.9 months and 1-, 2- and 5-year OS were $68.4 \%, 29.0 \%$ and $21.1 \%$, respectively.

Interval from surgery to start of radiotherapy (ISRT) Median ISRT was 18 days (range 5-78 days). In group 1 (receiving therapy within the first 17 days) the median interval to start of RTX was 12 days (range 5-17); in group 2 the median interval was 28 days (range 19-78). The delay of 78 days was an outlier and seen in a patient with GBM and local inconclusive biopsy who was referred late and only received treatment after re-evaluation of histology. Whereas all 4/30 patients starting RTX within the first week after surgery underwent biopsy only, ISRT was overall not significantly different in patients who only had biopsy compared to patients with debulking surgeries.

\section{Univariate analysis}

Overall survival There was no statistically significant difference in overall survival (OS) between groups (log-rank: $p=0.143$ ) (see Fig. 2a). Tumour grade (improved OS for grade 3 tumours, $p=0.020$ ) and EOR significantly influ- enced OS $(p=0.022)$. When comparing GTR to all other patterns of resection, significance was increased $(p=0.007)$ (see Fig. 2b). Resulting from univariate Cox regression analysis the hazard ratio (HR) of ISRT (continuous variable, $\log 2$-transformed) as a prognostic factor on OS was not statistically significant (HR $0.78,95 \%$ confidence interval [CI] 0.51-1.18, $p=0.231$ ). Grade (HR 2.33, CI 1.13-5.05, $p=0.022$ ) and EOR (HR 0.62, CI 0.44-0.84, $p=0.002$ ) statistically significantly influenced OS. OS was improved even further by GTR when compared to all other resections combined (HR 0.30, CI 0.11-0.72, $p=0.006$ ). Age was not identified as a statistically significant risk factor $(p=0.292)$.

Progression-free survival PFS was not statistically significantly different between groups 1 and 2 (log-rank: $p=0.126)$. Grade $(p=0.020)$ and GTR $(p=0.021)$ were statistically significantly associated with a superior PFS. In the univariate Cox regression models ISRT as a continuous variable ( $\log 2$-transformed; HR 0.74, CI 0.50-1.11, $p=0.142$ ) and dichotomised by group 1 and 2 (comparing longer to shorter intervals: HR 0.58 , CI $0.28-1.17$, $p=0.130$ ) as well as age (HR 0.97, CI 0.90-1.04, $p=0.361$ ) were not statistically significant; grade (HR 2.31, CI 1.13-4.98, $p=0.022$ ) and EOR (HR 0.65, CI 0.47-0.87, $p=0.004)$ were statistically significantly associated with PFS. 


\section{Multivariable analysis}

Overall survival EOR remained statistically significant in multivariable analysis (HR 0.23, CI 0.07-0.57, $p=0.0009$ ) and grade also reached significance (HR 3.02, CI 1.26-7.81, $p=0.013$ ), whereas an ISRT of $\geq 18$ vs. $\leq 17$ days did not (HR 0.82, CI 0.35-1.91, $p=0.643$ ). Considering ISRT as a continuous variable did not alter this finding (HR 0.95, CI $0.63-1.46, p=0.821)$.

Progression-free survival Grade (HR 2.76, CI 1.21-6.69, $p=0.015$ ) and EOR (HR 0.28, CI 0.10-0.66, $p=0.003$ ) were statistically significantly associated with PFS in multivariable analysis, but not ISRT dichotomised by group 1 and 2 (HR 0.71, CI $0.31-1.55, p=0.390$ ) or as a continuous variable (HR 0.85, CI 0.58-1.28, $p=0.432)$.

\section{Additional analyses}

In order to investigate the influence of adjuvant chemotherapy, we performed a survival analysis comparing patients receiving TMZ (10/38) to the remaining patients. Patients treated with TMZ exhibited a significantly better OS $(p=0.043)$ and PFS $(p=0.045)$ in univariate analysis. The survival benefit in OS was also found in multivariate analysis $(p=0.020$, HR 0.35 , CI $0.12-0.86$ ), but showed only a trend for PFS $(p=0.098$, HR 0.48, CI 0.17-1.14). Data on O-6-methylguanine-DNA methyltransferase (MGMT) status were not available.

When exploring a possible difference between patients treated within four weeks after surgery $(n=29)$ to those treated thereafter $(n=9)$, no significant difference either in OS $(p=0.655)$ or PFS $(p=0.447)$ could be identified.

\section{Discussion}

Like its adult counterpart paediatric high grade glioma (pHGG) has an unfavourable prognosis. In order to improve survival it is important to recognise potential influencing factors. Molecular subgrouping of pHGG [24] may influence treatment decisions in the future (e.g. presence of BRAF V600E mutations [25] or of a hypermutated phenotype [26] for which specific therapies are available). Since molecular subgrouping is often feasible in real time before starting adjuvant therapy [18], it is fundamental to identify a time limit that is safe to perform all necessary molecular testing. Prompted by a recent study involving a targeted drug that required a delay in start of radiotherapy for 4 weeks [27] we retrospectively analysed our consecutive series of patients above 3 years of age with HGG. As data on the best time point of radiotherapy in children with HGG are lacking, the present analysis evaluated a possible influ- ence of the interval from surgery to radiotherapy (ISRT) in this patient population. Unlike those postulated from other tumour entities [2] and defying radiobiological theorems [1], numerous adult studies could not detect a presumed negative influence of ISRT on patient survival in HGG [8-18]. A large study conducted by Blumenthal et al. [13] even suggested a favourable influence of prolonged waiting times until start of RTX. Similar to this observation ISRT could not be identified as a significant risk factor in our single-centre population of pHGG. Multiple factors may possibly influence such a finding like an uneven distribution of age, tumour grade or EOR. Whereas indeed our cohort of patients with the shortest ISRT comprised more patients with grade IV tumours, there was no significant difference in EOR or age. Studies involving adults found similar and even further bias: patients with unfavourable baseline characteristics and highly aggressive tumours seem to be over-represented in cohorts with shorter ISRT [6, 13-16]. In the large study by Blumenthal et al. [13] the cohort with shortest delays had worse scores of performance status and fewer gross total resections. This is underlined by findings of Spratt et al. [6] and Wang et al. [16]. Lai et al. [14] demonstrated that patients with biopsy only were more likely to be irradiated sooner after surgery. In an analysis by Wehming et al. [15] patients with an ISRT $<24$ days suffered more often from a grade IV tumour, had a minor EOR and a higher median age. Irwin et al. described a direct correlation of a better performance status to a prolonged ISRT [3]. Clinicians thus tend to apply RTX early in patients with a large tumour load and poor prognosis. This bias may consequently mask the effects of late treatment initiation.

In the present analysis only nine of 38 children were treated with an ISRT of more than 28 days. The overall length of ISRT in our cohort was therefore shorter than in the published data in adult HGG [13, 15, 18]. But, while overall ISRT seems longer in the adult population, only few patients with HGG had very long delays above 6 weeks, which is in contrast to studies in breast or head and neck cancer that identified a detrimental effect of delayed RTX [2]. In cohorts including patients with very long delays survival was impaired and it was deduced that delaying RTX beyond 6 weeks after surgery was a negative predictive factor [4-7]. Han et al. [17] even postulated an optimal time window of 30-34 days post-surgery, after which survival worsened. In contrast, studies postulating a positive effect of postponing RTX had a minority of patients with prolonged waiting times over 6 weeks, e.g. $0.7 \%$ [13] and 2.4\% [14], respectively. Considering that in our study $29 / 38$ patients started irradiation within 28 days after surgery this 4-week interval may be too narrow to cause significant differences in outcome. Yet, when comparing patients receiving RTX 
within four weeks or thereafter we could not even identify a trend towards a significant difference.

In addition to ISRT we also analysed other factors possibly influencing outcome in pHGG. Previous findings identified a higher extent of resection (EOR) [28-31] and lower tumour grade $[32,33]$ as major positive predictive factors for improved survival in pHGG. In accordance with the literature it was possible to reproduce the favourable influence of a greater EOR in univariate as well as multivariable analysis. Presence of a higher tumour grade could also be established to be associated with poorer PFS and OS. Young age as a predictor for favourable outcome [30, 32, 34] could not be evaluated in our cohort since patients under the age of 3 years (i.e. not receiving radiotherapy [19]) were excluded from the study.

Radiotherapy following surgery is considered the gold standard of HGG therapy in patients older than three years of age. Adjuvant chemotherapy was also used in all our patients but regimens varied over the past 2 decades. Interestingly and in contrast to previous findings [35], temozolomide (TMZ) seemed to be superior when compared to all other therapies in an exploratory analysis (the MGMT status being unknown in our retrospective cohort).

\section{Conclusion}

Our data therefore suggest the absence of a significant survival cost of moderate delays of simultaneous RCTX and waiting times of up to four weeks after surgery to be safely tolerable. The four week time frame may be used for molecular analysis needed for including patients with pHGG in future prospective clinical trials.

Funding Open access funding provided by Medical University of Vienna.

Conflict of interest A.A. Azizi, S. Paur, A. Kaider, K. Dieckmann, A. Peyrl, M. Chocholous, T. Czech and I. Slavc declare that they have no competing interests.

Open Access This article is distributed under the terms of the Creative Commons Attribution 4.0 International License (http:// creativecommons.org/licenses/by/4.0/), which permits unrestricted use, distribution, and reproduction in any medium, provided you give appropriate credit to the original author(s) and the source, provide a link to the Creative Commons license, and indicate if changes were made.

\section{References}

1. Wyatt RM, Beddoe AH, Dale RG (2003) The effects of delays in radiotherapy treatment on tumour control. Phys Med Biol 48(2):139-155

2. Huang J, Barbera L, Brouwers M, Browman G, Mackillop WJ (2003) Does delay in starting treatment affect the outcomes of radiotherapy? A systematic review. J Clin Oncol 21(3):555-563
3. Irwin C, Hunn M, Purdie G, Hamilton D (2007) Delay in radiotherapy shortens survival in patients with high grade glioma. J Neurooncol 85(3):339-343

4. Glinski B, Urbanski J, Hetnal M, Malecki K, Jarosz M, MuchaMalecka A, Chrostowska A, Jakubowicz E, Fraczek-Blachut B, Dymek P (2012) Prognostic value of the interval from surgery to initiation of radiation therapy in correlation with some histo-clinical parameters in patients with malignant supratentorial gliomas. Contemp Oncol 16(1):34-37

5. Valduvieco I, Verger E, Bruna J, Caral L, Pujol T, Ribalta T, Boget T, Oleaga L, Pineda E, Graus F (2013) Impact of radiotherapy delay on survival in glioblastoma. Clinical \& translational oncology. Off Publ Fed Span Oncol Soc Natl Cancer Inst Mexico 15(4):278-282

6. Spratt DE, Folkert M, Zumsteg ZS, Chan TA, Beal K, Gutin PH, Pentsova E, Yamada Y (2014) Temporal relationship of post-operative radiotherapy with temozolomide and oncologic outcome for glioblastoma. J Neurooncol 116(2):357-363

7. Sun MZ, Oh T, Ivan ME, Clark AJ, Safaee M, Sayegh ET, Kaur G, Parsa AT, Bloch O (2015) Survival impact of time to initiation of chemoradiotherapy after resection of newly diagnosed glioblastoma. J Neurosurg 122(5):1144-1150

8. Lutterbach J, Weigel P, Guttenberger R, Hinkelbein W (1999) Accelerated hyperfractionated radiotherapy in 149 patients with glioblastoma multiforme. Radiotherapy and oncology: journal of the European Society for Therapeutic. Radiol Oncol 53(1):49-52

9. Hulshof MC, Koot RW, Schimmel EC, Dekker F, Bosch DA, Gonzalez Gonzalez D (2001) Prognostic factors in glioblastoma multiforme. 10 years experience of a single institution. Strahlenther Onkol 177(6):283-290

10. Noel G, Huchet A, Feuvret L, Maire JP, Verrelle P, Le Rhun E, Aumont M, Thillays F, Sunyach MP, Henzen C, Missohou F, de Crevoisier R, Bondiau PY, Collin P, Durando X, Truc G, Kerr C, Bernier V, Clavier JB, Atlani D, D'Hombres A, Vinchon-Petit S, Lagrange JL, Taillandier L (2012) Waiting times before initiation of radiotherapy might not affect outcomes for patients with glioblastoma: a French retrospective analysis of patients treated in the era of concomitant temozolomide and radiotherapy. J Neurooncol 109(1):167-175

11. Seidlitz A, Siepmann T, Lock S, Juratli T, Baumann M, Krause M (2015) Impact of waiting time after surgery and overall time of postoperative radiochemotherapy on treatment outcome in glioblastoma multiforme. Radiat Oncol 10:172

12. Loureiro LV, Pontes Lde B, Callegaro-Filho D, Koch Lde O, Weltman E, Eda VS, Santos AJ, Borges LR, Segreto RA, Malheiros SM (2015) Waiting time to radiotherapy as a prognostic factor for glioblastoma patients in a. Scenario Med Disparities Arquivos De Neuro-psiquiatria 73(2):104-110

13. Blumenthal DT, Won M, Mehta MP, Curran WJ, Souhami L, Michalski JM, Rogers CL, Corn BW (2009) Short delay in initiation of radiotherapy may not affect outcome of patients with glioblastoma: a secondary analysis from the radiation therapy oncology group database. J Clin Oncol 27(5):733-739

14. Lai R, Hershman DL, Doan T, Neugut AI (2010) The timing of cranial radiation in elderly patients with newly diagnosed glioblastoma multiforme. Neuro-oncology 12(2):190-198

15. Wehming FM, Wiese B, Nakamura M, Bremer M, Karstens JH, Meyer A (2012) Malignant glioma grade 3 and 4: how relevant is timing of radiotherapy? Clin Neurol Neurosurg 114(6):617-621

16. Wang TJ, Jani A, Estrada J, Ung T, Chow DS, Soun J, Saad S, Qureshi YH, Gartrell R, Isaacson SR, Cheng SK, McKhann GM 2nd, Bruce JN, Lassman AB, Sisti MB (2016) Timing of adjuvant radiotherapy in glioblastoma patients: a single-institution experience with more than 400 patients. Neurosurgery 78:676-682. https://doi.org/10.1227/NEU.0000000000001036. PubMed PMID: 26440447 
17. Han SJ, Rutledge WC, Molinaro AM, Chang SM, Clarke JL, Prados MD, Taylor JW, Berger MS, Butowski NA (2015) The Effect of Timing of Concurrent Chemoradiation in Patients With Newly Diagnosed Glioblastoma. Neurosurgery 77(2):248-253 (discussion 253)

18. Adeberg S, Bostel T, Harrabi S, Bernhardt D, Welzel T, Wick W, Debus J, Combs SE (2015) Impact of delays in initiating postoperative chemoradiation while determining the MGMT promotermethylation statuses of patients with primary glioblastoma. BMC Cancer 15:558

19. Dufour C, Grill J, Lellouch-Tubiana A, Puget S, Chastagner P, Frappaz D, Doz F, Pichon F, Plantaz D, Gentet JC, Raquin MA, Kalifa C (2006) High-grade glioma in children under 5 years of age: a chemotherapy only approach with the BBSFOP protocol. Eur J Cancer 42(17):2939-2945

20. Schemper M, Smith TL. A note on quantifying follow-up in studies of failure time. Control Clin Trials (1996) 17(4), pp 343-346

21. Kaplan EL, Meier P (1958) Nonparametric Estimation from Incomplete Observations. J Am Stat Assoc 53(282):457-481

22. Cox DR Regression Models and Life Journal of the Royal Statistical Society Series B (1972) 34(2), pp 187-220

23. Heinze G, Schemper M (2001) A solution to the problem of monotone likelihood in Cox regression. Biometrics 57(1):114-119

24. Gajjar A, Bowers DC, Karajannis MA, Leary S, Witt H, Gottardo NG (2015) Pediatric Brain Tumors: Innovative Genomic Information Is Transforming the Diagnostic and Clinical Landscape. J Clin Oncol 33(27):2986-2998

25. Robinson GW, Orr BA, Gajjar A (2014) Complete clinical regression of a BRAF V600E-mutant pediatric glioblastoma multiforme after BRAF inhibitor therapy. BMC Cancer 14:258

26. Bouffet E, Larouche V, Campbell BB, Merico D, de Borja R, Aronson M, Durno C, Krueger J, Cabric V, Ramaswamy V, Zhukova N, Mason G, Farah R, Afzal S, Yalon M, Rechavi G, Magimairajan V, Walsh MF, Constantini S, Dvir R, Elhasid R, Reddy A, Osborn M, Sullivan M, Hansford J, Dodgshun A, Klauber-Demore N, Peterson L, Patel S, Lindhorst S, Atkinson J, Cohen Z, Laframboise R, Dirks P, Taylor M, Malkin D, Albrecht S, Dudley RW, Jabado N, Hawkins CE, Shlien A, Tabori U (2016) Immune Checkpoint Inhibition for Hypermutant Glioblastoma Multiforme Resulting From Germline Biallelic Mismatch Repair Deficiency. J Clin Oncol 34(19):2206-2211

27. Grill J, Hargrave D, Massimino M, Bouffet E, Azizi A, McCowage G, Canete A, Saran F, Le Deley MC, Varlet P, Morgan P, Jaspan T, Jones C, Smith H, Garcia J, Hilton M, Abrey L, Rousseau R, Vassal G (2016) BO25041-A phase II open-label, randomized, multi centre comparative study of Bevacizumab based on therapy in paediatric patients with newly diagnosed supratentorial, infratentorial cerebellar, or peduncular high grade glioma. Neuro-oncology 18:77-77

28. Finlay JL, Wisoff JH (1999) The impact of extent of resection in the management of malignant gliomas of childhood. Child's nervous system: ChNS. official journal of the International Society for Pediatric Neurosurgery. 1999;15(11-12):786-788

29. Kramm CM, Wagner S, Van Gool S, Schmid H, Strater R, Gnekow A, Rutkowski S, Wolff JE (2006) Improved survival after gross total resection of malignant gliomas in pediatric patients from the HITGBM studies. Anticancer Res 26(5B):3773-3779
30. McCrea HJ, Bander ED, Venn RA, Reiner AS, Iorgulescu JB, Puchi LA, Schaefer PM, Cederquist G, Greenfield JP (2015) Sex, age, anatomic location, and extent of resection influence outcomes in children with high-grade glioma. Neurosurgery 77:443-453. https://doi.org/10.1227/NEU.0000000000000845. PubMed PMID: 26083157

31. Wolff JE, Gnekow AK, Kortmann RD, Pietsch T, Urban C, Graf N, Kuhl J (2002) Preradiation chemotherapy for pediatric patients with high-grade glioma. Cancer 94(1):264-271

32. Qaddoumi I, Sultan I, Gajjar A (2009) Outcome and prognostic features in pediatric gliomas: a review of 6212 cases from the Surveillance, Epidemiology, and End Results database. Cancer 115(24):5761-5770

33. Walston S, Hamstra DA, Oh K, Woods G, Guiou M, Olshefski RS, Chakravarti A, Williams TM (2015) A multi-institutional experience in pediatric high-grade glioma. Front Oncol 5:28

34. Sanders RP, Kocak M, Burger PC, Merchant TE, Gajjar A, Broniscer A (2007) High-grade astrocytoma in very young children. Pediatr Blood Cancer 49(7):888-893

35. Cohen KJ, Pollack IF, Zhou T, Buxton A, Holmes EJ, Burger PC, Brat DJ, Rosenblum MK, Hamilton RL, Lavey RS, Heideman RL (2011) Temozolomide in the treatment of high-grade gliomas in children: a report from the Children's Oncology Group. Neuro-oncology 13(3):317-323

36. Wolff JE, Driever PH, Erdlenbruch B, Kortmann RD, Rutkowski S, Pietsch T, Parker C, Metz MW, Gnekow A, Kramm CM (2010) Intensive chemotherapy improves survival in pediatric high-grade glioma after gross total resection: results of the HIT-GBM-C protocol. Cancer 116(3):705-712

37. Wolff JE, Kortmann RD, Wolff B, Pietsch T, Peters O, Schmid HJ, Rutkowski S, Warmuth-Metz M, Kramm C (2011) High dose methotrexate for pediatric high grade glioma: results of the HITGBM-D pilot study. J Neurooncol 102(3):433-442

38. Stupp R, Mason WP, van den Bent MJ, Weller M, Fisher B, Taphoorn MJ, Belanger K, Brandes AA, Marosi C, Bogdahn U, Curschmann J, Janzer RC, Ludwin SK, Gorlia T, Allgeier A, Lacombe D, Cairncross JG, Eisenhauer E, Mirimanoff RO (2005) European Organisation for R, Treatment of Cancer Brain T. Radiotherapy G, National Cancer Institute of Canada Clinical Trials G (Radiotherapy plus concomitant and adjuvant temozolomide for glioblastoma. N Engl J Med 352 (10):987-996.)

39. Buchroithner J, Pichler J, Marosi C, Widhalm G, Seiz-Rosenhagen M, Novosielski M, Oberndorfer S, Ruckser R, Rossler K, Azizi A, von Campe G, Bordihn K, Felzmann T (2014) Vascular endothelia growth factor targeted therapy may improve the effect of dendritic cell-based cancer immune therapy. Int J Clin Pharmacol Ther 52(1):76-77

40. Bode U, Massimino M, Bach F, Zimmermann M, Khuhlaeva E, Westphal M (2012) Fleischhack G Nimotuzumab treatment of malignant gliomas. Expert Opin Biol Ther 12(12):1649-1659

41. Massimino M, Biassoni V, Miceli R, Schiavello E, Warmuth-Metz M, Modena P, Casanova M, Pecori E, Giangaspero F, Antonelli M, Buttarelli FR, Potepan P, Pollo B, Nunziata R, Spreafico F, Podda M, Anichini A, Clerici CA, Sardi I, De Cecco L, Bode U, Bach F (2014) Gandola L Results of nimotuzumab and vinorelbine, radiation and re-irradiation for diffuse pontine glioma in childhood. J Neurooncol 118(2):305-312 